\title{
DIFFERENCES IN RESEARCH ABSTRACTS WRITTEN IN ARABIC, FRENCH, AND ENGLISH
}

\author{
Abdelmajid Bouziane and Fatima Ezzahra Metkal \\ Faculty of Letters and Humanities Ben M'Sik, \\ Hassan II University of Casablanca
}

\begin{abstract}
The proliferation of publications, mainly the digital ones, makes it necessary to write well-structured abstracts which help readers gauge the relevance of articles and thus attract a wider readership. This article investigates whether abstracts written in three languages, namely Arabic, French and English, follow the same patterns within or across languages. It compares 112 abstracts in the areas of (applied) linguistics. The English abstracts include 36 research article (RA) abstracts from an Arab journal mostly written by non-natives and 10 by native speakers from British universities. Those produced in French are 36 divided into two sets, 23 from North African journals and the remaining 13 from French journals. The Arabic abstracts consist of 30 abstracts, 15 from North African journals mainly from Tunisia, Algeria, and Morocco and the other 15 from the Middle East with a focus on Qatari and Saudi texts. Results emanating from the frequency of moves show that the abstracts written in English by natives and non-natives and those produced in Arabic by Middle Eastern writers show conformity with the existing conventions of abstract writing in English. However, those from North Africa, be they Arabic or French, do not share any specific patterns which can be attributed to the language in which they are written. Further research is needed to check whether abstract writing is part of the academic writing curriculum in these two latter languages.
\end{abstract}

Keywords: differences, abstracts, Arabic, French, English

Article history:

Submitted: 25 May 2020

Reviewed: 27 November 2020

Accepted: 1 December 2020

Published: 21 December 2020

\begin{abstract}
Contributor roles:
Conceptualization; Supervision; Validation; Writing - review and editing: A.B. (lead); Methodology: F.E.M. (lead), A.L. (supporting) Investigation; Formal Analysis: A.B., F.E.M. (equal); Data curation; Visualization; Project Administration; Writing - original draft: F.E.M.(lead)
\end{abstract}

Copyright (C) 2020 Abdelmajid Bouziane and Fatima Ezzahra Metkal

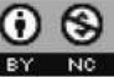

This open access article is published and distributed under a CC BY-NC 4.0 International License which permits non-commercial use, distribution, and reproduction in any medium, provided the original author and source are credited. Permissions beyond the scope of this license may be available at a.bouziane@flbenmsik.ma. If you want to use the work commercially, you must first get the authors' permission.

Citation: Bouziane, A. and Metkal, F. E. (2020). Differences in Research Abstracts written in Arabic, French, and English. English Studies at NBU, 6(2), 233-248. https://doi.org/10.33919/esnbu.20.2.4

Abdelmajid Bouziane is a professor of education at Hassan II University of Casablanca, Morocco. He has served as a project manager and participant in different national and international projects related to education. He has published widely in the areas of teaching English as a foreign language, ICT, and education in general. He serves as a peer reviewer for some international journals. His areas of interest are: TEFL, ICT in education, research methods, teachers' associations, and language policy. He has supervised several master and doctorate theses.

E-mail: a.bouziane@flbenmsik.ma

https://orcid.org/0000-0002-4138-2450

Fatima Ezzahra Metkal is a teacher of English in high school. She earned a master's degree in Moroccan American Studies from the Faculty of Letters and Humanities Ben M'Sik, Casablanca. 
The increasing number of publications, mainly the digital ones, and the lack of time to read them have resulted in a strong need for well-elaborated abstracts. Particularly in educational research, Miech et al. (2005) raise the challenge of too many articles published every year and propose an appropriate structuring of the abstract to overcome three challenges the practitioners face: access, time and motivation to make use of findings in so many articles. They claim that the existing formats need more refinements to have effective impact on practitioners:

The structural innovation we propose here specifically addresses the 20,000 article problem: how to help millions of people in education connect with the tens of thousands of articles published each year in education journals that might prove useful to them in practice. We believe that the structured abstract, an innovation that focuses on the format of the article itself, can help overcome the existing impediments to disseminating the findings of research. (Miech et al. 2005, pp. 397-398; italics in the original).

Practically, the authors suggest a more detailed and structured abstract format which can guide potential practitioners to make good use of the findings of educational research. Their template consists of nine components: (1) Background / Context, (2) Purpose / Objective / Research Question / Focus of Study, (3) Setting, (4) Population / Participants / Subjects, (5) Intervention / Program / Practice, (6) Research Design, (7) Data Collection and Analysis, (8) Findings / Results, and (9) Conclusions / Recommendations (p. 399). In other fields, the rapidly increasing number of publications, with the proliferation of online journals, and the higher number of research productions resulting from the growing enrolments in graduate studies (see this growth in education throughout history in Newsom, 2011) have made abstracts more important. To guide readers and writers, some languages have developed abstract writing conventions (see for example ANSI/NISO, 1997 for abstracts of experimental, descriptive, or discursive studies) whereas others are still in the process of doing so and thus abstracts may differ across languages.

Abstract quality is a determinant predictor for accepting a paper in a conference and for reading the rest of the article or thesis. It has become mandatory that the candidates who intend to apply for conferences or for degrees to be aware of abstract writing conventions and to study them as part of their academic writing curriculum. However, abstract writing conventions are salient in some languages but less so in 
others. It is the intent of this article to investigate the components of abstracts in three languages, namely Arabic, French and English, with the aim of looking into the features of the abstracts that prevail in these languages in linguistics or applied linguistics. It tries to answer the following research questions:

- Which moves occur in the abstracts produced in English, Arabic and French?

- How similar, or different, are the abstract features produced in Arabic by two groups belonging to two geographical regions?

\section{Literature review}

This paper is interested in abstract writing which is informed with the studies related to genre. Although the term genre has various interpretations (see the review of literature in Stein, 1997), a working definition adopted for this study has been suggested by Swales (1990):

A genre comprises a class of communicative events, the members of which share some set of communicative purposes. These purposes are recognized by the expert members of the parent discourse community and thereby constitute the rationale for the genre. This rationale shapes the schematic structure of the discourse and influences and constrains choice of content and style. (p. 59).

In his book, Swales (1990) aims to provide a reference which will help tutors give specific tasks to students to come up with the intended activity (see Part I of the book). To do so, he developed his model (Swales, 1990) and later together with Feak (Swales \& Feak, 2009) labelled CARS model (Create-A-Research-Space). This model contains three moves, namely, establishing a territory (consisting of three steps), establishing a niche (four steps), and occupying the niche (four steps). A different model by Hyland (2000) contains five moves: Introduction (M1), Purpose (M2), Method (M3), Product (M4) instead of results in other models, and Conclusion (M5). He used it to compare the research article (RA) abstracts in eight different disciplines. As this study adopts this model, it is worth providing more details about it. Introduction establishes context for the paper and invites readers for discussions. Purpose indicates the purpose, the problematic of the study (thesis), the research questions or hypothesis, and orients the reader to the rationale of the paper. Method summarizes the design, the tools used for data collection and data analysis. Product presents the main findings and sometimes discusses them. Conclusion extends the results beyond the scope of the paper and thus draws inferences and describes implications. The reviewed models have been adopted, 
with some variants sometimes, in various research studies (see below) with focus on frequency of moves in abstracts in different disciplines and languages.

Following the above models, and others, abstract structure has been studied from three major perspectives, namely investigating the abstracts within the same discipline, across disciplines and across languages. For example, within the same discipline, Stein (1997) discusses many models to try to work out why some abstracts ( $n=237$ ) were accepted, and others rejected in the 1996 TESOL convention. He aimed to describe the characteristics of an abstract genre. He divides the abstracts in his data into two types: empirical and pedagogical with a focus on the fields of research and ESL in higher education. He adopts the IMRD (Introduction, Methods, Results, and Discussion) for empirical abstracts and the ILF (Introduction, Lecture, and Finale) for pedagogical ones. He finds that in both types of abstracts the occurrence of major moves does not determine accepting or rejecting an abstract. Rather, an abstract genre features the highest frequency of Introduction, followed by Methods, then Discussion and finally Results as the lowest frequency. Some sub-moves and the (non)occurrence of citations make a difference, too, but these are beyond the scope of this article. He concludes that "A genre is not only defined by the frequency of its moves and submoves, and their obligatory and optional natures, it is also defined by the purpose it serves its discourse community. Different genres have different moves and different purposes." (p. 224). In this same area, Wang and Tu (2014) analyse abstracts in applied linguistics $(n=1000)$ selected evenly from four well-known journals. They find that the use of the present tense of 'to be' dominates but the use of present or past tenses with other verbs varies across journals and especially across the parts of the abstract. They also report the frequent adoption of the IMRD model, followed by Hyland's model and then CARS (see above) and especially that M3, M4 and M5 in the Hyland's model (see above) prevail in the studied abstracts. Quite a similar study came to the same findings, Can et al. (2016) studied the abstracts in the issues of one journal of applied linguistics from 2011 to 2013 ( $n=50$ ). They confirm the occurrence of purpose, methodology and findings in the abstracts while around half did not include introduction or discussion. Another study by EL-Dakhs (2018) compares abstracts taken from indexed journals $(n=200)$ with non-indexed ones $(n=200)$. The findings show that the abstracts in the non-indexed journals contain longer moves of M1, M2, M3 while in the indexed ones, longer M4 are more frequent. 
The other perspective of research compares abstracts written in different languages or by native and non-native speakers. Fallatah (2016), adopting the model of abstract structure by Swales and Feak (2009), analyses 93 abstracts written by Saudi authors in English (n=37), Saudi authors in Arabic $(n=27)$ and international authors $(n=29)$. Her comparison of these abstracts shows that the international abstracts contain almost all the moves except M1 with $45 \%$ of occurrence and, quite equally, the Saudi Arabic abstracts have more consistency as they contain at least three main moves (M2, M3, and M4) but only 10\% of M1 and 0\% of M5. However, the Saudi English abstracts contain fewer moves with the occurrence of M2 in $90 \%$ of the abstracts and the range of $45 \%$ to $75 \%$ of the occurrence of other moves. She attributes the scarcity of M1 in the Arabic abstracts to the fact that Arab writers are reader-based as opposed to the western style which is writer-based. Similarly, she justifies the presence of the introduction (M1) in the Saudi English abstracts for being addressed to western readership. Similarly, using Swales' model to compare abstracts produced by native speakers and those by non-natives (Chinese), Ji (2015) has found that while Chinese scholars focus on Introduction, the native speakers focus on Method and Result. Within this same framework, Tabatabaei et al. (2016) have studied the abstracts produced by non-natives. They have adopted Swales' eleven-step model to analyse 30 abstracts in the MA theses by Iranian students in TEFL. They find that the most equally predominant steps (24\% of the sample) belong to the Occupying niche move and they are Outlining Purposes, Announcing Present Research, and Announcing Main findings. The occurrence of the other eight steps in their model ranged between 1 and 10\%. Equally, Briones (2018) who used Hyland's model (2000) analysed 29 abstracts taken from three journals based in North Africa and the Middle East. The findings confirm that M2, M3 and $\mathrm{M}^{\prime}$ are the predominant moves in those abstracts. But they happen to be in a different sequence from the one set by Hyland.

The third perspective examines abstracts across disciplines and sometimes across languages using Hyland's model (see above). Alotaibi (2013) has compared abstracts in two disciplines, educational psychology, and sociology, and in two languages, English and Arabic (see other studies in Alotaibi, 2013. pp. 54-57). The findings show that all the disciplines and languages share the three frequent moves reported thus far but they differ. The abstracts in English contain more introduction and conclusion moves and the 
abstracts of psychology contain more conclusion moves while those in sociology contain more of the introduction ones. Similarly, Benham and Golpour (2014) adopted this model to compare the abstracts in two disciplines, applied linguistics and mathematics, and in two languages, English and Persian. The selected abstracts (n=80, 20 RA of each discipline and each language) include quite the same moves in both languages in applied linguistics with slight differences in Introduction and Conclusion; however, the math abstracts contain quite different moves in the two languages. Katc and Safranj (2018) use the same model to compare abstracts in 12 disciplines $(n=12)$. They refined the application of the model using Kanoksilapatham's (2005) criteria of frequency of the moves as obligatory, optional, and conventional with the occurrence rate of $100 \%$, below $60 \%$, and between 60 and 99\%, respectively. They have found, across the investigated disciplines, that Introduction and Purpose moves are obligatory, Methodology and Conclusion show variations whereas Product is the mostly omitted. Other differences are reported by Çakır (2016) who compares 240 abstracts written by Turkish and native writers of English using Hyland and Tse's model (2005) across six disciplines, three of which are pure and the others are soft sciences. This study focuses on the use of stance adverbs. It shows that native writers use more stance adverbs than their Turkish counterparts. It also reports that writers in soft sciences use more stance adverbs than those in pure sciences. Quite similar results are reported in a study by Darabad (2016) who compares 21 abstracts from each of journals of applied linguistics, applied mathematics and applied chemistry $(\mathrm{n}=63)$. His results report that Purpose and Product appear in nearly all the studied abstracts, followed by Method, then Conclusion and Introduction.

This review has surveyed the use of two models of analysis for analysing the abstracts with the tendency to the frequent use of Hyland's (2000). The studies in this review have covered those that compare abstracts in different languages, statuses of the used languages, disciplines, and types of journals. Like the previous studies, this one adopts the same model but differs in comparing abstract writing within and across the three most used languages in the MENA region to investigate their approaches to the writing of abstracts. 


\section{Methodology}

The collected data consist of 112 abstracts divided into five sets from the field of (applied) linguistics. The abstracts in English contain 36 RA abstracts that appeared in the Arab World English Journal and 10 abstracts from dissertations written by winners or finalists of researchers in ELT which were taken at random from the British Council website $^{1}$. The English abstracts were produced by native and non-native speakers of the language. The non-natives' English level is academically native-like as their texts appeared in master or PhD dissertations. The French texts constitute 36 RA abstracts; 23 of them were taken from different North African journals whereas the other 13 texts from French journals. They have been produced by writers belonging to different countries but with a high proficiency of French. As for the Arabic texts which constitute of 30 abstracts, 15 of them were taken from North African journals mainly from Tunisia, Algeria, and Morocco, the other 15 abstracts are produced by writers from the Middle East with a focus on Qatari and Saudi texts. These writers are natives of Arabic.

To analyse the above abstracts, the present study adopts Hyland's (2000) fivemove schema to identify the structural pattern in the investigated abstracts. Every move of the adopted model executes a structural task, that of carrying out a "communicative purpose". According to this model, the five moves are: Introduction (M1), Purpose (M2), Method (M3), Product (M4), and Conclusion (M5) (see the description of Hyland's model in the Literature review above).

The "top-down approach" is adopted to determine the dividing lines of the moves in the analysed abstracts together with classifying the role of each move in its respective abstract. Generally, the operation of identifying and classifying every move in the collected abstracts was relatively straightforward with 93 Cronbach's alpha coefficient between the two authors of this article in a sample of four abstracts from each subset $(n=24)$.

\section{Findings and Discussion}

This section introduces the findings of the cross-linguistic analysis of the Arabic, French and English abstracts together with some suggested interpretations for the explanation of the results obtained from the data analysis.

\footnotetext{
${ }^{1}$ https://englishagenda.britishcouncil.org
} 
Table 1

Frequency of moves occurrence in the five sets of abstracts

\begin{tabular}{lccccc}
\hline \multicolumn{1}{c}{ Move } & $\begin{array}{c}\text { English } \\
\text { (AWE) }\end{array}$ & $\begin{array}{c}\text { English } \\
\text { (British } \\
\text { universities) }\end{array}$ & French & $\begin{array}{c}\text { Arabic } \\
\text { (Middle } \\
\text { East) }\end{array}$ & $\begin{array}{c}\text { Arabic } \\
\text { (North } \\
\text { Africa) }\end{array}$ \\
\hline 0. Zero move & $0(0 \%)$ & $0(0 \%)$ & $3(8 \%)$ & $1(7 \%)$ & $8(53 \%)$ \\
1. Introduction & $19(53 \%)$ & $6(60 \%)$ & $18(50 \%)$ & $5(33 \%)$ & $2(13 \%)$ \\
2. Purpose & $36(100 \%)$ & $10(100 \%)$ & $31(86 \%)$ & $14(93 \%)$ & $7(46 \%)$ \\
3. Method & $33(92 \%)$ & $10(100 \%)$ & $19(52 \%)$ & $11(73 \%)$ & $3(20 \%)$ \\
4. Product & $32(89 \%)$ & $10(100 \%)$ & $9(25 \%)$ & $12(80 \%)$ & $2(13 \%)$ \\
5. Conclusion & $14(39 \%)$ & $9(90 \%)$ & $5(14 \%)$ & $1(7 \%)$ & $1(7 \%)$
\end{tabular}

The findings, in Table 1, indicate that the purpose move (M2) is the most recurrent and compulsory move in the five types of texts. The table also shows that English (AWEJ) and Arabic (AME) abstracts share the M2-M3-M4 pattern that arises as the typical design in the abstracts in both languages. The French and Arabic (ANA) abstracts share the presence of the purpose move (M2) and the method move (M3). The table also shows that M2, M3, and M4 are obligatory moves in English (British universities) abstracts. Besides, the ten selected texts show a respect for the rhetorical moves of writing an abstract. This entails that there exists a British tradition by which writers should abide.

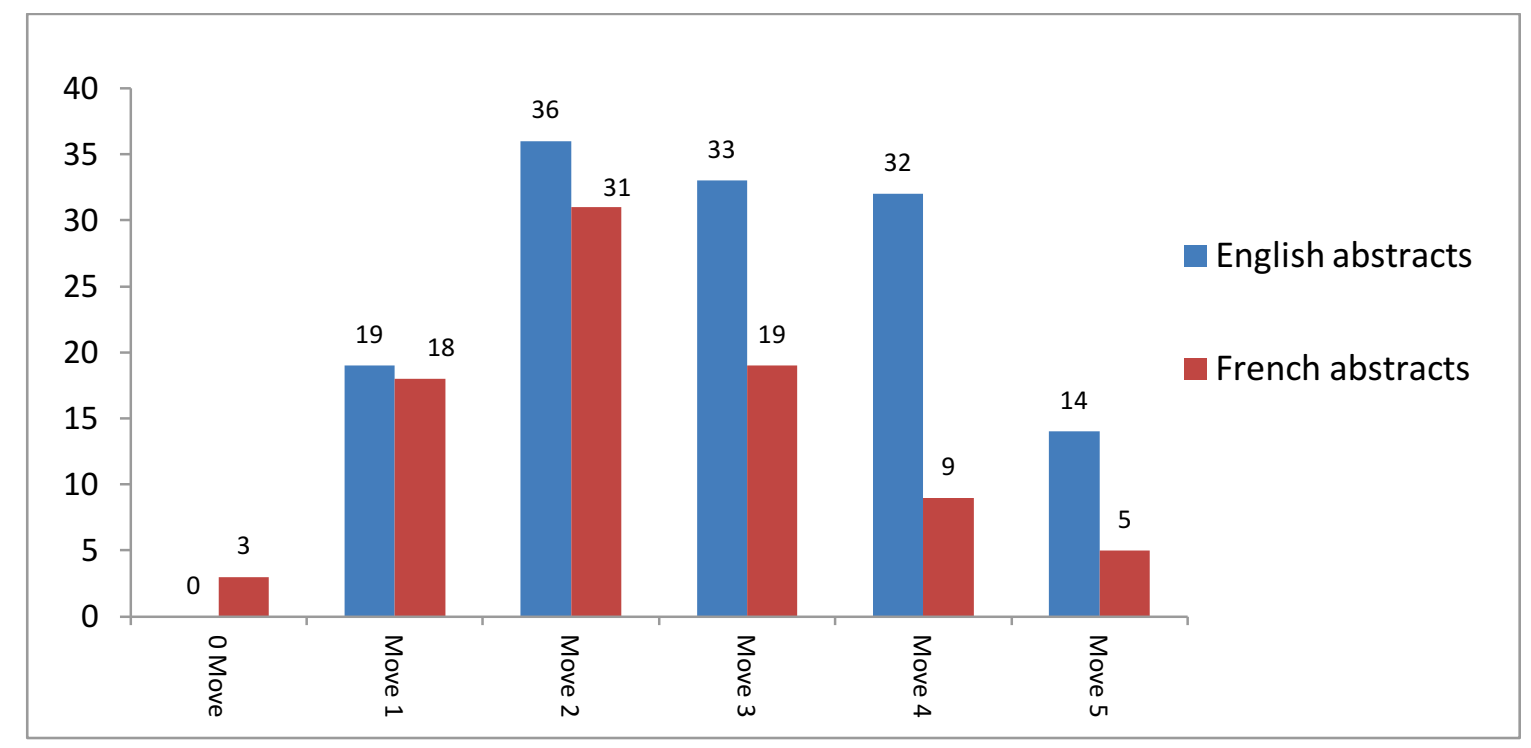

Figure 1. Moves in English and French abstracts (data from British universities excluded) 
Figure 1 demonstrates that in the French and the English abstracts, the common moves are the introduction (M1) and the purpose (M2). However, the abstracts in French contain fewer other moves and three of them (8\%) contain 0 move.

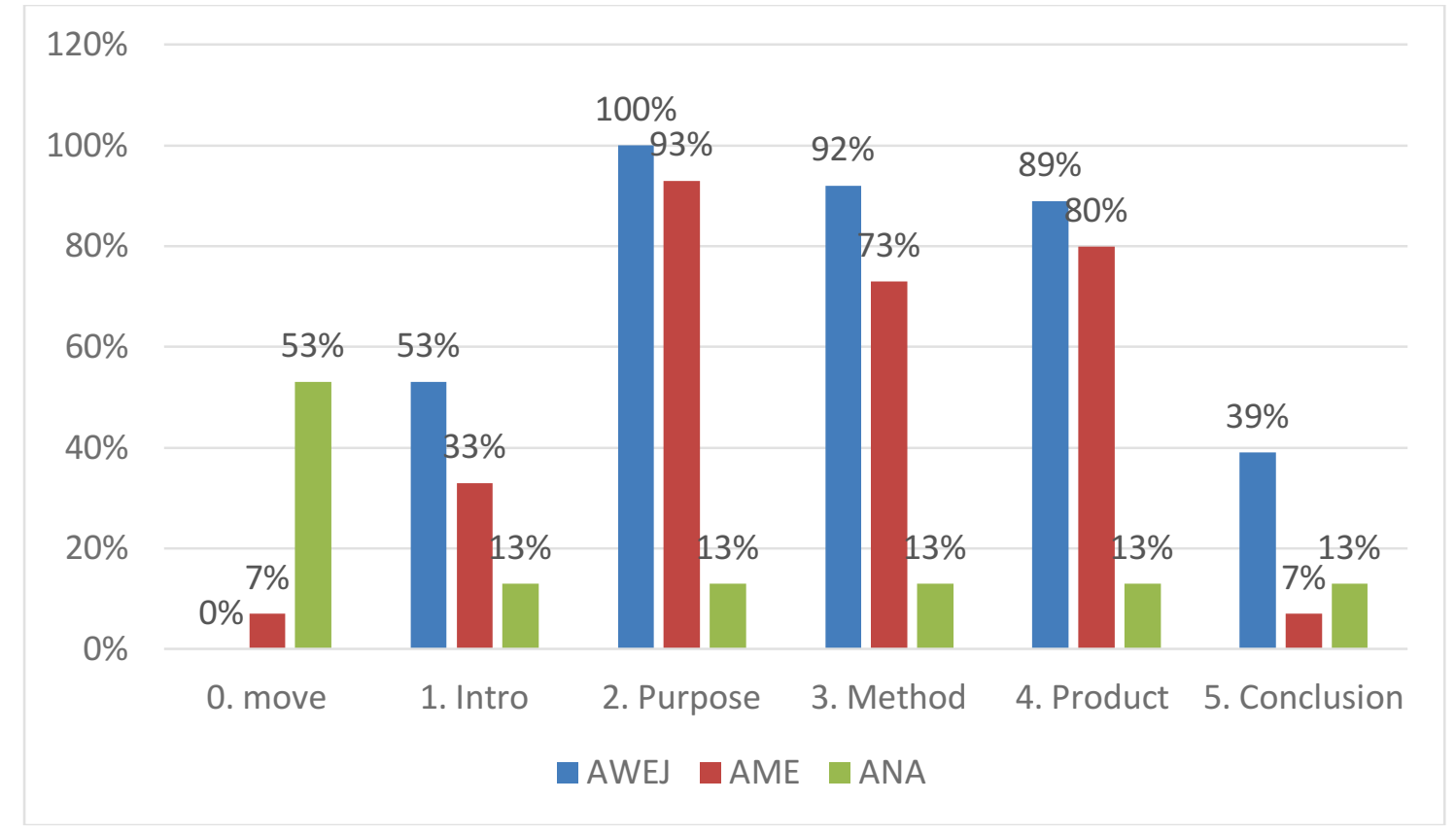

Figure 2. Comparison of English (AWEJ), Arabic (ME), and Arabic (NA) abstracts

Figure 2 indicates that the abstracts in Arabic by North African authors differ from those in English (AWEJ) and in Arabic from the Middle East. Both AWEJ and AME share the M2-M3-M4 patterns while the ANA abstracts are the least structured with fewer or no moves.

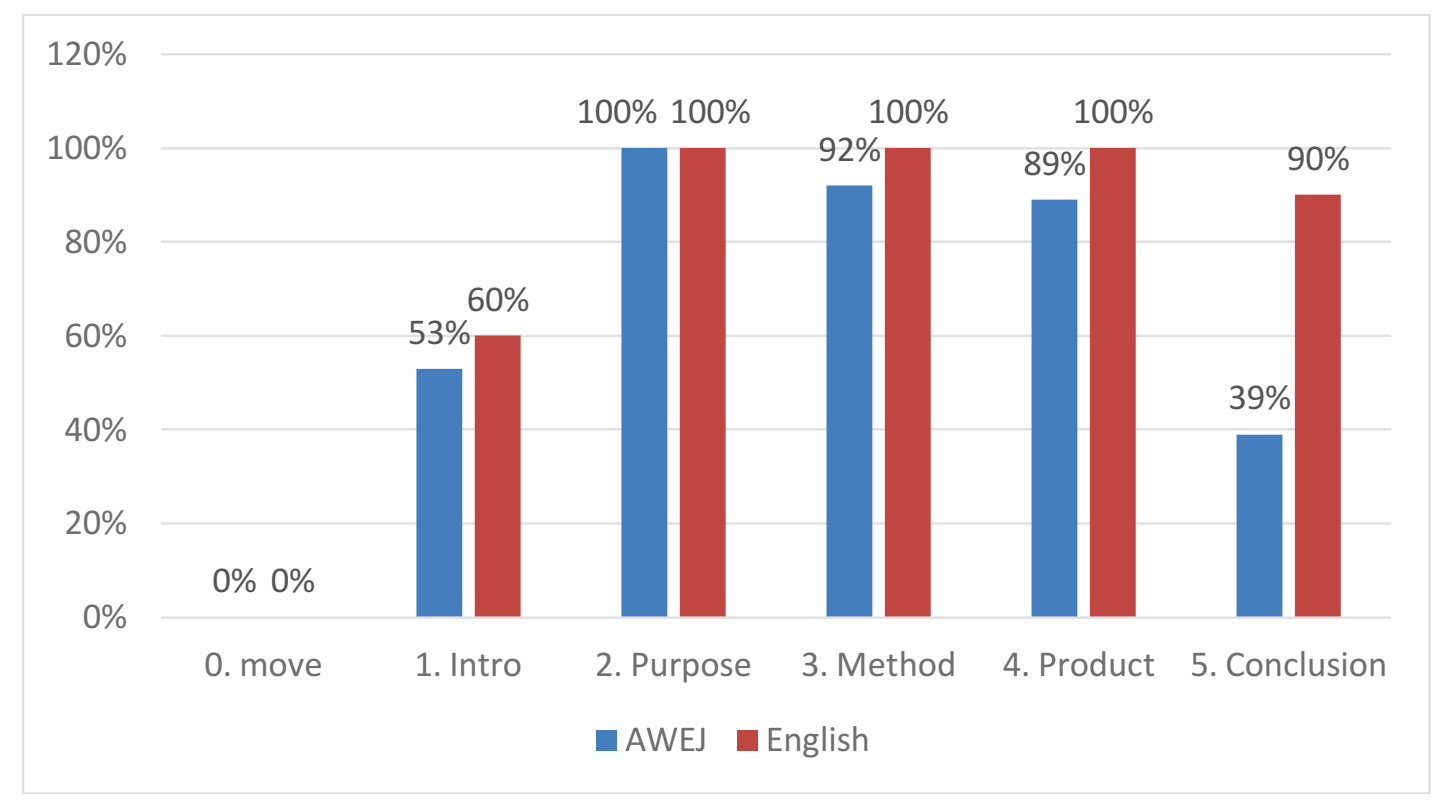


Figure 3. Comparison of English (AWEJ) and English (British universities) abstracts

This third graph demonstrates that English (AWEJ) and English (British universities) abstracts meet in high moves occurrence that consequently structure most of these target abstracts with an M1-to-M5 pattern. The only substantial difference lies in the presence of more Conclusion moves in the British universities.

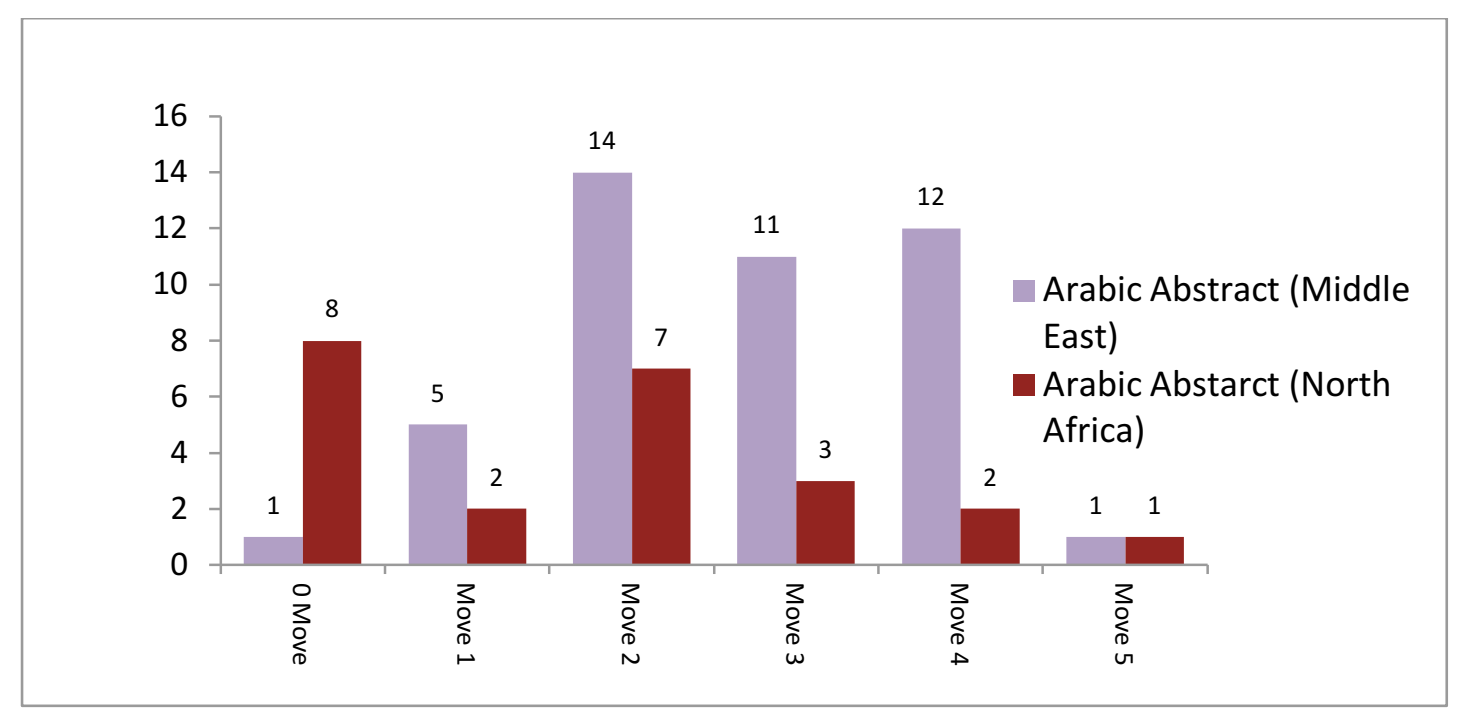

Figure 4. Comparison of moves in abstracts in Arabic: Middle East vs. North Africa

Figure 4 shows big variations of move frequency in the two compared data sets except for the conclusion move (M5) that share the same percentage in both groups and which occurs less frequently. It also shows that the Middle Easterners are closer to the English tradition of abstract writing than the North Africans. 53\% of the latter's abstracts contain 0 move.

Based on the above findings, the answer to the first research question indicates that the English data, no matter who produces it, contain an important number of the five moves which implies that their authors are awareness of the use of moves when writing RA abstracts in English. The most shared moves among the abstracts written in English are M2-M3-M4 patterns. This confirms the existence of a structural convention that is respected by the writers in English. It is worth mentioning that some online publishing websites require the writing of a structured abstract for the advantages this offers for both the reader and the writer. Some French data, however, include no move and are just summaries of the research papers under focus whereas the rest of the abstracts include only two moves. This implies that the French authors need more 
awareness about the conventional patterns of writing abstracts. French authors tend to focus on both the purpose move (M2) and the Product move (M3). The findings emanating from the analysis of the Arabic abstracts confirm that the authors from the Middle East share more moves, the M2-M3-M4 patterns, than their North Africa counterparts. This suggests that most authors from this category not only are aware of the conventional pattern based on the English academic discourse community but also transfer this know-how to their productions in Arabic. However, a bigger percentage of summaries is found in the ANA data. Some of the North African authors include no move while the rest of the abstracts share either the M1-M2 or the M2-M3 structure.

The results of the study also report some common features across the languages. The Purpose move is found in almost every abstract and thus turns out to be an obligatory move in the five types of texts. This suggests that describing the aim of the study is an essential element of the abstracts in the three languages. It is also found that an important number of abstracts from the five sets of texts contain M2 as an initial move. The M2 sometimes occurs as an independent move but at other times it is embedded within the Method move (M3) depending on the author's focus.

The comparison of the abstracts in Arabic produced by two groups belonging to two geographical areas has yielded very interesting outcomes. Theses abstracts show a lot of differences in the distribution of moves. The Middle Easterners' abstracts show a lot of similarities with those by authors in English while the North Africans' contain a limited number of moves. It seems that the differences in abstract writing are far from being determined by the language factor. The two sets of data written in Arabic differ because the writers from the Middle East are more aware of the English tradition of abstract writing than their North African counterparts. It should be acknowledged that the authors in the $A W E J$ data are non-native researchers who attempted to follow the English abstract writing conventions. This confirms that abstract writing in English requires knowing the English writing conventions which help articles reach wider readership. The ANA texts, on the other hand, have the M2-M3 structure in common and share them with the French texts. The abstracts in the two languages are characterised by move deletion. The lack of awareness of abstract writing in the two languages may be the origin of the differences reported in the findings. 
The findings of this study indicate that the writers' degree of familiarity with the moves of an abstract determines conformity with or deviation from abstract structure. It should be stressed that the abstract writing in English is the most studied by many genre analysts and therefore it shapes a tradition which is more salient and has become part of the curriculum of academic writing. The abstracts produced in the two other languages, French and Arabic, need further studies in the hope of working out the patterns that will meet their potential readers' expectations.

\section{Implications}

The findings from the cross-linguistic analysis in the present study can serve, in general, in raising graduate students' awareness to the moves in research articles, the linear order, and the role each move plays in abstract writing. This awareness will have another interface in better understanding of abstracts. More specifically, the results and the knowledge gained from this study can help authors who produce articles in Arabic and French to better understand the existing variations in RA structures across languages. Such understanding will pave the way for designing guidelines in respective languages for an abstract structure that depends largely on the academic communities' preferences. However, the well-established models in English can already serve as a framework for designing an explicit abstract structure in other languages. The researchers writing in these languages will acquire international recognition especially with the increasing process of globalization of the academic communities through internationalising universities.

After designing the abstract structures specific to a language, the second implication has to do with teaching them. Teaching students, especially graduate students, the specific features of each move and how to deploy it in abstract writing is the basis for converging towards standardising and conformity. These students will produce papers with an academic discourse in conformity with the writing standards of the international academic community. In the long run, research in different languages will yield universal patterns of abstract writing to make good use of research and its findings. The potential target pattern can start from the premise of conventional English move-schema. However, further research on abstracts written in French and Arabic will result in developing a move-pattern of their own and suggest it to be considered when drafting an abstract. 
Despite the number of studies on abstract writing in English, some challenges persist. The investigations in different disciplines show inconclusive results. Montesi \& Owen (2007) have found that the revision of abstracts, prior to uploading them in databases, consists of only some minor spelling or shortening the text corrections. They attribute this practice to the lack of guidelines by the LISA (Library and Information Science Abstracts). Ebrahimi \& Chan (2015), who compared abstracts in applied linguistics to those in economics, claim that the writer's discipline sometimes informs the structure of abstract writing. Vrijhoef \& Steuten (2007) report that many journals do not provide adequate guidelines of abstract writing and thus many of them contain unstructured abstracts. They also report that some medical publications either contain inconsistent data or do not process the data given in abstracts. Structured abstracts, according to these authors, will meet three objectives: "(1) to inform readers better, (2) to improve search retrieval, and (3) to facilitate peer review." (p. 125). Ross et al. (2006) provide evidence that adopting blinded peer review in abstract acceptance has reduced bias to geography location (favouring US over non-US universities), institution prestige, and linguistic belonging (English-speaking authors were favoured).

\section{Limitations and further research}

Like other studies, this study has limitations which can turn into further research topics. The research method adopted in the present study is purely quantitative and the calculations are done based on the frequency of move occurrences. There is a need for investigating the functions of the moves together with the type of abstract. For example, further studies across the three languages are worth doing in terms of evidentiality (Yang \& Tian, 2015). Another limitation lies in the comparisons of the outcomes in three languages without further research on the structures of abstracts in each language and how it compares with the ones in the other languages. To provide enough evidence, more research studies are required to understand what the readers, especially the researchers, of these languages expect in an abstract and whether graduate students are exposed to an input of how to write an abstract in their academic curriculum. Universities, consortia and libraries should agree on the structure of an abstract in each of the two under studied languages to provide adequate guidelines for (potential) researchers to produce abstracts that will be accepted by their peers in their scientific communities. 


\section{Conclusion}

This study has investigated the structure of abstracts in one field of study in three languages. The comparisons report a lot of differences which are not related to languages per se. Rather, they are related to two other factors. First, the existence of a salient tradition of abstract writing that is explicitly stated in the literature for potential researchers to follow. The number of studies reported in English is still increasing in the hope of better understanding how to serve the different communities of researchers and consumers of research. Second, the degree of familiarity with the abstract writing. The example of the abstracts written in Arabic by the researchers from the Middle East explains this factor. These researchers might have been exposed to abstract writing or inspired by their readings of research in English. Such input is needed in the two other languages in this article.

\section{References}

Alotaibi, H. (2013). Research Article Abstracts and Introductions: A Comparative GenreBased Study of Arabic and English in the Fields of Educational Psychology and Sociology. [Unpublished doctoral dissertation]. Texas A\&M University-Commerce.

ANSI/NISO (1997). Guidelines for Abstracts. NISO Press.

Behnam, B. \& Golpour, F. (2014). A Genre analysis of English and Iranian research articles abstracts in applied linguistics and mathematics. International Journal of Applied Linguistics \& English Literature, 3(5), 173-179. https://doi.org/10.7575/aiac.ijalel.v.3n.5p.173

Briones, R. R. Y. (2018). Move analysis of abstracts in applied linguistics research: The Middle East and North Africa (MENA) perspective. Asian Journal of English Language Studies (AJELS), 6, 25-55.

Can, S.; Karabacak, E.; \& Qin, J. (2016). Structure of moves in research article abstracts in applied linguistics. Publications, 4(23), 2-16.

https://doi.org/10.3390/publications4030023

Çakır, H. (2016). Native and non-native writers' use of stance adverbs in English research article abstracts. Open Journal of Modern Linguistics, 6, 85-96. https://doi.org/10.4236/ojml.2016.62008

Darabad, M. A. (2016). Move analysis of research article abstracts: A cross-disciplinary study. International Journal of Linguistics, 8(2), 125-140. https://doi.org/10.5296/ijl.v8i2.9379 
Ebrahimi, S. F \& Chan, S. H. (2015). Research article abstracts in applied linguistics and economics: Functional analysis of the grammatical subject. Australian Journal of Linguistics, 35(4), 381-397.

EL-Dakhs, D. A. (2018). Comparative genre analysis of research article abstracts in more and less prestigious journals: Linguistics journals in focus. Research in Language, 16(1), 47-63. https://doi.org/10.2478/rela-2018-0002

Fallatah, W. (2016). Features of Saudi English research articles abstracts. Arab World English Journal, 7(2), 368-379. https://doi.org/10.24093/awej/vol7no2.25

Hyland, K. (2000). Disciplinary Discourses: Social Interactions in Academic Writing. Longman.

Ji, X. L. (2015). Comparison of abstracts written by native speakers and second language learners. Open Journal of Modern Linguistics, 5, 470-474.

https://doi.org/10.4236/ojml.2015.55041

Kanoksilapatham, B. (2005). Rhetorical structure of biochemistry research articles. English for Specific Purposes, 24, 269-292. https://doi.org/10.1016/j.esp.2004.08.003

Katic M., Safranj J. (2018). An Analysis of Dissertation Abstracts Written by Non-native English Speakers at a Serbian University: Differences and Similarities Across Disciplines. In Chitez M., Doroholschi C., Kruse O., Salski Ł., Tucan D. (Eds.), University Writing in Central and Eastern Europe: Tradition, Transition, and Innovation. Multilingual Education, vol 29. Springer. https://doi.org/10.1007/9783-319-95198-0 16

Miech, E. J.; Nave, B.; \& Mosteller, F. (2005). The 20,000 Article Problem: How a Structured Abstract can Help Practitioners Sort out Educational Research. The Phi Delta Kappan, 86(5), 396-400. https://doi.org/10.1177/003172170508600512

Montesi, M. and Owen, J. M. (2007). Revision of author abstracts: how it is carried out by LISA editors. Aslib Proceedings: New Information Perspectives, 59(1), 26-45. https://doi.org/10.1108/00012530710725197

Newsom, T. W. (2011). A Critical Analysis of Ph.D. and Ed.D. Dissertation Abstracts Published During 2009 And 2010. [Unpublished doctoral dissertation]. University of North Texas.

Ross J. S., Gross C. P., Desai, M.M., Hong, Y., Grant, A.O., Daniels, S.R. Hachinski, V. C., Gibbons, R. J. Gardner, T.J. Harlan M. Kumholz, H. M. (2006). Effect of Blinded Peer Review on Abstract Acceptance. JAMA. 295(14), 1675-1680. https://doi.org/10.1001/jama.295.14.1675

Stein, W. (1997). A Genre Analysis of the TESOL Conference Abstract. [Unpublished doctoral dissertation]. University of Central Oklahoma. 
Swales, J. M. (1990). Genre analysis: English in academic and research settings. Cambridge University Press.

Tabatabaei, S. P.; Najafi, Z., and Gobadirad, H. (2016). The Rhetorical Structure of M.A. Abstracts Written by Students of English Language Teaching in Iran. Modern Journal of Language Teaching Methods (MJLTM), 6(2), 535-543.

Vrijhoef, HJM \& Steuten, LMG (2007). How to write an abstract. European Diabetes Nursing, 4(3), 124-127 https://doi.org/10.1002/edn.93

Wang, W. (2002). Optimal Components of Research Publication Abstracts: Producing Abstracts that Meet the American National Standards. [Unpublished doctoral dissertation]. The University of Mississippi.

Wang, S. P. \& Tu, P. N. (2014). Tense use and move analysis in journal article abstracts. Taiwan Journal of TESOL, 11(1), 3-29.

Yang, L. X., \& Tian, Y. (2015). A Cross-disciplinary study of evidentiality in abstracts of English research articles. Open Journal of Modern Linguistics, 5, 399-411. https://doi.org/10.4236/ojml.2015.54036 